\title{
Ortopedi ve Travmatoloji dalının diğer tıp dalları ile rekabeti
}

\section{Competition of orthopedics and traumatology with other medical branches}

\author{
Sait Ada
}

EMOT Hastanesi Kurucusu, Genel Ortopedi ve Travmatoloji Uzmanı, El Cerrahisi Uzmanı, İzmir

\begin{abstract}
Tıp insan sağlığının farklı sorunları ile uğraşırken, bazen aynı sorun farklı uzmanlık dallarının ortak alanı olabilir. Bu nedenle örtüşen hastalık gruplarının tanı ve tedavisinde, farklı dallar birbiri ile rekabete girebilir. Rekabetin bilimsel düzeyde ve işbirliği içinde olması çok önemlidir, ancak pratik yaşamda bu rekabet genellikle olumsuz şekilde olmakta ve ekonomik rekabete dönüşebilmektedir. Ortopedi ve Travmatolojinin de kesiştiği uzmanlık dalları, özellikle El Cerrahisi ve Spinal Cerrahidir. Ayrıca, bazı dâhili dallar ve son zamanlarda Geleneksel, Tamamlayıcı ve Alternatif Tıp gibi yöntemleri uygulayanlarla da konularımız örtüşmektedir. Burada, hastanın dallar arasında ne zaman kime yönlendirilmesi gerektiği, en kritik noktadır. Hastanın, durumuna ve hastalığına göre diğer uzmanlık dalına veya konu kendi uzmanlık alanımızda olsa bile yeterli eğitim veya koşullarımız yoksa başka bir meslektaşımıza yönlendirilmesi çok önemlidir. Sonuç olarak; tüm dallar arasında rekabetin hasta ve halk sağlığı yararına olması gerekir. Hekimliğin temel ilkeleri olan bilimsel ilkeler ışığında çalışma ve etik kurallara uyma en büyük rehberimiz olmalıdır.
\end{abstract}

Anahtar sözcükler: rekabet; ortopedi ve travmatoloji; diğer uzmanlık dalları
While the branches of specialty in medicine deal with different problems of human health, sometimes the same problem can be common areas of different specialties. Different branches may compete with each other in the diagnosis and treatment of these overlapping disease groups. It is very important for competition to be scientific and to cooperate, but in general practical life, this competition is generally negative and can turn into a form of economic competition. The competitiveness of Orthopedics and Traumatology with its specialties is particularly in the areas of hand surgery and spinal surgery. In addition, some internal branches overlap our patients. This is the most critical point when to refer the patient to the branches. It is very important to refer the patient to the other specialty according to the condition of the disease and the patient, or to refer to another colleague if there is not enough training or conditions, even if it is in our own field of expertise. As a result; competition between all branches must be for the benefit of patients and public health. In the light of scientific principles, which are the basic principles of medicine, working and obeying ethical rules should be our biggest guide.

Key words: competition; orthopaedics; medical branches
$\mathbf{R}$ ekabet, ilk bakışta yeniliğe açık olma ve iyiye ulaşmanın yöntemi olarak tanımlanmasının yanı sıra, çağımızda neoliberal yapının olmazsa olmazıdır. Neredeyse tüm dünyaya hâkim olan neoliberal düzen, iş ve sosyal yaşamın her alanında, akademik yaşamda ve daha birçok konuda-dijital çağın getirdiği olanaklarla- müthiş bir rekabet ortamı yaratarak yaşamı ve dünyayı şekillendirmektedir. Mesleğimiz de bundan etkilenmiş ve hekimler bireysel veya kurumsal rekabet içine girmişlerdir. Bu rekabet, akademik açıdan olumlu olmasına rağmen, ekonomik açıdan olumsuzluklar içermektedir. Ortopedi ve Travmatoloji ile ortak hasta grubu olan dallar arasında; Plastik ve Rekonstrüktif Cerrahi, Beyin ve Sinir Cerrahisi, Fizik Tedavi ve Rehabilitasyon, Algoloji, Romatoloji ile Geleneksel, Alternatif ve Tamamlayıc Tıp (GATT) bulunmaktadır. Bu dallarla Ortopedi ve Travmatoloji arasındaki rekabet alanları ve sorunlarını üç bölümde inceleyeceğiz.

\section{ORTOPEDI VE TRAVMATOLOJi ILE DIĞER CERRAHI DALLAR ARASINDA REKABET}

Ortopedi ve Travmatoloji ile en fazla rekabet El Cerrahisi ve Spinal Cerrahi alanlarında olmaktadır.

- İletişim adresi: Prof. Dr. Sait Ada, EMOT Hastanesi 1418 Sok. No:14 Kahramanlar, İzmir

Tel: 0532 - 7716848 e-posta: sait_ada@yahoo.com

- Geliștarihi: 9 Ekim 2019 Kabul tarihi: 11 Kasım 2019 


\section{El Cerrahisi}

El Cerrahisi, ekip çalışması gerektiren, gece ve gündüz acil karşılaması ve uzun ameliyat süreleri olan bir daldır. El cerrahisinin dünyada ve ülkemizdeki gelişiminde Ortopedi ve Travmatoloji ile Plastik ve Rekonstrüktif Cerrahi dallarının büyük katkıları olmuştur. Her iki daIın olumlu rekabeti sonucu, bugün el cerrahisi yapan meslektaşlar arasında akademik ve hastaya yönelik olumlu bir rekabet vardır. Kongre ve dernek çalışmalarında, meslektaşların hak ve hukukunun savunulmasında, genel olarak yardımlaşma, etik kurallara saygı ve sevgi olduğu söylenebilir.

El Cerrahisi yan dalının kurulması sonucu, yan dal eğitimi ile her iki dalın uzmanları kendi alanlarındaki eksikliklerini tamamlamakta ve el cerrahı ünvanını almaktadırlar. Ancak, ülkemizdeki sağlık sistemi ve acil organizasyonundaki sorunlar, ciddi özlük sorunları (ana dalda ve özel sektörde aynı zamanda çalışamamaları gibi vb.), çok önemli alt yapı ve organizasyon yetersizlikleri El Cerrahisi yan dalının en önemli sorunlarıdır. El cerrahisi uzmanları; gerek ekonomik gerekse çalışma koşulları nedeniyle bugün çok mutsuzdurlar. Uzmanlıklarını almadan istifa etmektedirler ve yerlerine yeni el cerrahları gelemeyebilir. Tüm bu nedenlerle, el cerrahisi alanında olumsuz rekabetin olmaması, yan dalın getirdiği olumsuzluklara bağlı olması gibi ironik bir durum olabilir. Yani tersten okuyunca, cazibenin kalkması olumlu bir ilişki yaratsa da, koşulların düzeltilmemesi meslektaşları mutsuz etmekte ve EI Cerrahisi, gerek ana dallarda gerekse yan dal olarak ilgi kaybetmektedir. Sonuçta, esas etkilenen elbette hastalarımız olmaktadırlar.

\section{Spinal Cerrahi}

Omurga Derneğinin başkanlığını da yapmış olan Prof. Dr. Teoman Benli'nin konu ile ilgili görüşleri şöyledir: Ortopedi ve Travmatoloji ile Beyin ve Sinir Cerrahisi de aralarında rekabet yaşanan dallardır. Tarihsel olarak bakıldığında çocuk cerrahisinden ayrılarak kurulan Ortopedi, çocuk omurga hastalıkları ve başta skolyoz olmak üzere omurga deformitelerinin tedavilerini baştan beri üstlenmiş durumdadır. Birçok toplumda olduğu gibi ülkemizde de, bel ağrısı olan hastaların, bu bir bel fitığı olabilir diye yönlendirildikleri hekimler ise beyin ve sinir cerrahlarıdır.

Ortopedistler 1960'lardan sonra, skolyotik deformitelerin tedavisinde Harrington rodları ve çengeller kullanmaya başladılar. Sadece füzyon yaptıkları Pott hastalığında geç kifoz deformitesinin önlenmesi için de enstrümantasyon uyguladılar. Hem skolyoz gibi koronal hem de kifoz gibi sagittal plan deformiteler, 1980'lerin sonlarında daha modern sistemler
(Cotrel-Dubousset -CD) kullanıma girdikten sonra daha başarılı olarak düzeltilmeye başlandı. Sonraları, servikal ve lomber spinal stenoz, spondilolistezis, omurga enfeksiyonları ve tümörleri konusunda da enstrümantasyon kullanarak tedavi etmeyi uygulamaya soktular. Beyin cerrahları, bu dönemde, disk cerrahisi ve spinal stenozda laminektomi ile dekompresyon dışında bir şey yapmıyorlardı.

Birçok beyin cerrahı, enstrümantasyon yapmayı 1990'lardan sonra ortopedistlerden öğrendi. Beyin cerrahları bu dönemde skolyoz hastalarına pek dokunmadılar ama "biz de omurga hastalıkları için cerrahi tedavi uyguluyoruz" diyerek, kendilerini doğal omurga cerrahı saydıklarını ifade ettiler. Yabancı şirketler, "pazar” payını artırmak için, gittikçe daha çok beyin cerrahının eğitimi için çaba gösterdi.

Amerika Birleşik Devletleri'nde (ABD) benzer gelişmeler yaşandı: “omurga cerrahisi” 1980'lerde bir üst ihtisas alanı (fellowship) haline geldi; üniversiteler, Skolyoz Araştırma Derneği (SRS) gibi dernekler ihtisas programları düzenleyip, sertifikalar vermeye başladı. Ortopedistlerin \%80 gibi bir çoğunluğa sahip oldukları SRS ve beyin cerrahların \%80 çoğunluğa sahip oldukları Kuzey Amerika Omurga Derneği (NASS) gibi iki meslek örgütü kuruldu. Bu dernekler omurga cerrahisi eğitimi vermeye ve sertifikasyona başladı. Halen özellikle bu iki dal arası çekişme Amerika Birleşik Devletleri ve Avrupa'da sürmektedir.

Kuruluşunda üyelerin tamamı Ortopedi ve Travmatoloji uzmanı olan Türk Omurga Derneği, yaklaşık 14 yıl boyunca TOTBID ile yakın ilişkiler içinde omurga cerrahisi kongreleri ve kurslar düzenledi, ulusal kongrelerdeki Omurga Oturumlarını organize etti. illk defa 2003 yılında, birkaç beyin ve sinir cerrahı Türk Omurga Derneği'ne üye olarak alındı ve kurslara katılmaları sağlandı. Yönetim Kurulundaki iki dalın temsil hakları, 2011 yılında \%50-\%50 olarak sınırlandı. 2015 yılında, Türk Tabipleri Birliği (TTB) ikna edilerek, beyin cerrahisi ile Ortopedi ve Travmatoloji listeleri dışında ayrı bir omurga cerrahisi başlığı altında, eksik girişimler tamamlanarak bir TTB listesi yapılması sağlanmıştır. Sosyal Güvenlik Kurumu (SGK) ise bir revizyon yapmayarak bazı kalemlerin Ortopedi ve Travmatoloji, bazı kalemlerin ise Beyin ve Sinir cerrahisinde kalması durumunu değiştirmemekte ve olumsuz bir rekabete neden olmaktadır.

Sonuç olarak; spinal cerrahide öğrenme eğrisinin uzun olması ve çoğu eğitim kliniğinde omurga cerrahisi yapılmaması, spinal cerrahi ile ilgilenen Ortopedi ve Travmatoloji uzmanı sayısının azalmasına yol açmıştır. Buna karşılık, spinal cerrahi ile uğraşan beyin ve sinir cerrahisi uzmanlarının sayısı artmakta ve spinal cerrahi Beyin ve Sinir Cerrahisinin alanıymış gibi bir algı 
oluşmaktadır. Bu konudaki çözüm ise omurga cerrahisinin Anabilim Dalı haline gelmesi, hem Ortopedi ve Travmatoloji hem de Nöroşirurji Asistan Eğitimi programlarından çıkartılmasıdır. Ya da diğer bir çözüm, ABD'de olduğu gibi en az iki yıllık yan dal eğitim programının kurulmasıdır.

Dışardan gözlemci olarak görüyorum ki; spinal cerrahi ile uğraşan Ortopedi ve Travmatoloji uzmanı sayısı azalmaktadır. Beyin ve Sinir cerrahları lehine asimetrik bir rekabet vardır. Akademik ve tarihsel olarak bizlerin deformite düzeltmeye daha yetkin olduğumuz ve skolyoz, kifoz cerrahisindeki alanımızı bırakmamamız gerektiğini düşünüyorum. Bu konuda yan dal uygulaması iyi bir çözüm olabilir; ancak, El Cerrahisinde olduğu gibi zorunlu hizmet, ana dalda çalışma kısıtlaması ve özel sektörde çalışamama gibi sorunlar doğurabilir. Bu sorunların sağlık otoriteleri tarafından çözülmesi gerekmektedir.

\section{ORTOPEDI VE TRAVMATOLOJi ILE DÂHILi BRANŞLAR ARASI REKABET}

Uzmanlık dalımızın; Fizik Tedavi ve Rehabilitasyon (FTR), Romatoloji, Endokrinoloji ve Nöroloji ile rekabeti mevcuttur. Ortak alanlarımız olarak; osteoporoz tedavisi, tuzak nöropatileri, romatolojik hastalıklar, serebral felç ilk akla gelenlerdir. Asıl sorun ortak hastalıklar değil, bu hastalıklarda tedaviye hangi dalda başlanıp, hastanın daha sonra ne zaman diğer ilgili dala sevk edileceğidir. Aşağıda, kişisel görüşlerim olarak, dâhili dallardaki bazı ortak alanların sorunlarına değinmek istiyorum.

Osteoporoz tedavisinin, Ortopedi ve Travmatoloji veya FTR alanında olmadığını ve Endokrinoloji dalının bu konuda daha yetkin olduğunu düşünüyorum. Çünkü osteoporoz, primer ya da sekonder olsun, sonuçta bir hormonal değişim sonucu oluşmaktadır. Bizlerin, cerrahi tedavi yoğunluğumuz içinde, osteoporozun etiyolojisini araştırmak ve ilaç kullanımını planlamakta bazı zorluklarımız olduğunu düşünüyorum. Bazı meslektaşlarımız bu konuda kendini çok iyi yetiştirmiş olsa da, dalımızın genel yoğunluğu içinde bu tedaviyi Endokrinoloji dalına terk edebiliriz düşüncesindeyim.

Yaygın veya bölgesel artroz, tuzak nöropatileri, tetik parmak, tenisçi dirseği vb. olayların erken dönemlerinin FTR uzmanlarınca izlenip, konservatif tedavilerinin yapılabileceğini düşünüyorum. Ancak, cerrahi endikasyon sınırına gelmiş hastaların bizlere sevk edilmemesinin de olumsuz bir rekabet biçimi olduğu ortadadır. İleri artrozların Ortopedi ve Travmatoloji uzmanı görüşü alınmadan konservatif tedaviye devam ettirilmesi, tuzak nöropatilerinde kas atrofileri sonrası hastanın sevki gibi olumsuz durumlar sıkça karşımıza çıkmaktadır. Serebral palsi de, hem FTR hem de Ortopedi ve Travmatoloji uzmanlarının ortak izlemesi gereken hastalıklardandır. Oluşturulan ortak çalışma grupları ile çok iyi izlenen bir hastalık türü olsa da, serebral palsi çoğunlukla sadece fizik tedavi ile izlenir ve cerrahi tedavi yapılmaz diyen bir FTR uzmanı grubu da vardır.

Benzer sorun Romatoloji ile Ortopedi ve Travmatoloji dallarının ortak hasta grubunda da vardır. Romatoloji dalının tanı ve medikal tedavide önemi büyüktür ve bu tedavi onlar tarafindan düzenlenmelidir. Ancak, atellemeler ve gerekirse cerrahi tedavi ile hastanın fonksiyonel ilerlemesinin sağlanması için, iyi bir işbirliğine gereksinim vardır. Bazı üniversite ve eğitim hastanelerinde bu işbirliği konseyler aracılığı ile ortak protokollerle sağlanırken, özel hekimlik ve özel hastanelerde bu konuda önemli sorunlar vardır ve hastalar olumsuz rekabete örnek olacak uygulamalara maruz kalmaktadırlar. Romatoloğun, deformite gelişmiş bir hastada Ortopedi ve Travmatoloji uzmanının görüşünü istememesi veya FTR uzmanının cerrahiden daha fazla yarar görecek hastayı Ortopedi ve Travmatoloji uzmanına göndermemesi gibi örnekler verilebilir. Aynı durum tersine şekilde, FTR'den ya da medikal tedaviden yarar görecek bir hastaya cerrahi tedavi yapanlar için de geçerlidir. Bu örnekler çok artırılabilir, ancak esas önemli olan, hekimin kendi uzmanlık dalındaki endikasyonu dışında, hastayı doğru zamanda ve doğru endikasyonu ile, onun lehine başka bir uzmanIık dalına yönlendirmesini sağlamaktır. "Hasta kaybı" (ekonomik rekabet) gibi olumsuz bir rekabet içerisinde olmak, hastaya zarar veren etik dışı bir durumdur.

\section{GELENEKSEL, TAMAMLAYICI VE ALTERNATIF TIP ILE REKABET}

Sağlık Bakanlı̆̆ı'nın yönetmeliği ile yürürlüğe giren Geleneksel, Alternatif ve Tamamlayıcı Tıp (GATT) uygulamaları her alanla çakışan ciddi bir olumsuz rekabet yaratmıştır. Bu yöntemi uygulayan meslektaşlarımız, kısa süreli kurslarla sertifika da almakta ve bu alanda "tedavi" uygulamaktadırlar. Bu uygulamalar için çok geniş endikasyonlar belirlenmiştir. Örneğin, ağrı bu tip uygulamalar için en sık endikasyondur. Ağrının nedenleri anlatmaya sayfalar yetmez iken, malign bir kemik tümörünün ilk belirtisinin hafif bir ağrı olduğunu hepimiz bilmekteyiz. Ancak, yönetmelikteki endikasyonların çoğunda, kas, eklem ağrıları ve genel ağrılar gibi genel tanımlarla, her alanda ve özellikle alanımızı ilgilendiren semptomlar bulunmaktadır. Bu yöntemler maalesef bazı Sağlık Bakanlığı hastanelerinde ve özel hekimlikte sıkça kullanılmaya başlamıştır; ayrıca, medya ve sosyal medya reklamları ile de yaygın hale gelmektedir. Kupa, hacamat, sülük ve birçok GATT yöntemi bilimle çelişmektedir. 
Konunun TTB ve Uzmanlık Dernekleri tarafindan izlenmesi halk sağlığı açısından çok önemlidir. Bu konuda TTB'nin 2017 yılında bastırdığı “Tıbbın Alternatifi Olmaz! Geleneksel Alternatif ve Tamamlayıcı Tıp Uygulamaları" kitapçı̆̆ını okumanızı öneririm.

\section{SONUÇ}

Ülkemizdeki tıp uygulamaları içinde dallar arası rekabet genel olarak olumsuz niteliktedir ve sıklıkla ekonomik rekabet örnekleridir. Bu olumsuzluktan Ortopedi ve Travmatoloji uzmanları da nasiplerini almaktadırlar. Performans Sistemi ve Sağlık Uygulama Tebliği (SUT) konularındaki sorunlar, özel hekimlik ve özel hastane koşulları bu olumsuz rekabeti körüklemektedir. Hasta-hekim ilişkisinde, hastanın anlama ve karşılaştırma gücü sınırlıdır. Hekimin hastasına yarar sağlayacağını bilmediği ve/veya bilimsel olarak kanıtlanmamış tedavileri uygulaması, kendi uzmanlık alanına girmeyen hastalıkları veya alanında deneyimsiz olduğu hastaları tedavi etmesi uygun değildir. Bu nedenle, hekimlikte meslek etiği kuralları her dönemde önemli olmuştur.
Aslında Tıp Etiği en eski ve hâlâ en yaygın olan etik konusudur. Koslowski bunu; "Hekimlik etkinliği sadece teknik bilgi ve beceriyi yerine getirmekle kalmamalı, aynı zamanda hem pragmatik buyruklar ve hem de hastanın birey olarak tanınmasının getirdiği hakları içeren bir etik buyruk olarak yapılmalıdır." ifadesiyle belirtmiştir. ${ }^{[1]}$ Yani hekimlik; hem teknik (bilgi ve beceri) hem pragmatik (çözümcü) hem de etik boyutları olan bir meslektir, teknisyenlik değildir. Özellikle meslek etiğinde, belirli bir mesleği icra ederken ne yapılması gerektiğine dair sorulara mesleğin bazı normlar getirmesi gereğidir. Kuşkusuz her sorunun bir normu oluşmamış olabilir; kişinin bunu yaşam boyu elde ettiği etik kavramlara ve bilimsel verilere göre değerlendirmesi gerekir. Bunu sağlamak için; iyi bir standart eğitim müfredatı, meslek sonrası düzenli eğitim ve etik dışı olayların sorgulanıp cezalandırılmasını sağlayacak kontrol sisteminin olması gerekmektedir.

\section{KAYNAK}

1. Koslowski P. Etik ve Hekimlik Sanatı. İçinde: Tepe H, editör. Etik ve Meslek Etikleri -Tıp, Çevre, İş, Basın, Hukuk ve Siyaset. Hacettepe, Ankara: Türkiye Felsefe Kurumu Yayınları; 2001. ss. 47-56. 